\title{
TRAINING NEEDS OF MILITARY STUDENTS ON INTERCULTURAL COMPETENCE
}

\author{
Florentina-Lavinia MATEI \\ University of Bucharest, Romania \\ mateilavinia92@yahoo.com \\ Florentina-Ionela LINCĂ \\ University of Bucharest, Romania \\ linca.florentina@gmail.com
}

\begin{abstract}
The present research aims to identify the training needs of military students and their perceptions about the importance and necessity of training the intercultural competence, before participating in an international mobility stage. Their mobility takes place within the international Erasmus Plus program. The questionnaire that was the basis of this research had two dimensions. Following the processing of the results, it was found that the students need to be well trained before interacting with a new culture.
\end{abstract}

KEYWORDS: intercultural competence, military students, training needs, training program

\section{Introduction}

In recent decades, student mobility has increased significantly, the most popular international mobility program being Erasmus Plus. Both the process of globalization and the European policy of promoting intercultural competences, determine institutions to recognize that students need to be prepared for the challenges arising from international contacts. Thus, several European universities have developed their own training program for intercultural competence, preparing students for an international mobility stage.

This intercultural competence prepares students to live in a multicultural society and offers them the opportunity to create interpersonal contacts that represent the key elements in the field of education.
2. The Need for the Training of Intercultural Competence

More and more studies are talking about the need to train students' intercultural competence before participating in an international mobility stage.

In the international specialized literature, there are numerous studies that have investigated the aspects of intercultural competence or its impact on students who are in an international mobility stage. According to the authors of the article Developing an intercultural competence program at an international cross-border university (Hiller \& Wozniok, 2009), intercultural competence is one of the most requested skills. The authors of the study speak about the initiative of the Viadrina University in Germany, which has developed a program with the aim of 
forming intercultural competence, one of its main aims being to help students discover and discuss the diversity of cultural values in special workshops, thus being prepared for the challenges of international mobility stages.

The article Innovative methods for promoting and assessing intercultural competence in higher education (Hiller, 2010) presents some of the training methods used in the program developed by the university mentioned above. The methods used in the program are role play and critical incident analysis, which aim to create a holistic learning effect.

Another university that emphasizes the formation of intercultural competence is the Nancy University of France. We note from the article Designing an intercultural program to prepare students to study abroad (Zumbehl, 2010) that the program created by this university emphasizes the acquisition of knowledge about culture, the management of negative emotions and misunderstandings.

Only from the study of these articles that support the formation of intercultural competence, it is noted that this competence is given significant importance in universities in Europe, such as the Viadrina University in Germany and the Nancy University in France. Thus, on the basis of them, we can conclude that the formation of intercultural competence is a fundamental basis for the accomplishment of an stage of international mobility, producing positive effects in the experiences of the interns students, leading also to the increase of the motivation to realize such a stage.

\section{Research Methodology}

\subsection{Objective of Research}

O1. Determining students' perception of the role and importance of intercultural competence;

O2. The students' appreciation of the elements that contribute to the effective communication with the members belonging to another culture;
O3. Determining the students' perception of possible obstacles during the mobility stage;

O4. Analysis of students' opinions on the legitimacy of a program for training the intercultural competence and its desirable characteristics.

\subsection{Sample of Research}

The study was attended by 45 students $(\mathrm{N}=45)$, from the Academy of Land Forces "Nicolae Bălcescu" in Sibiu, 18 male and 27 female, aged between 20 and 27 years, before their participation in an stage for international mobility.

\subsection{Method and Research Tool}

In this study, the students were given a questionnaire before participating in the international mobility stage, its purpose being to identify the training needs regarding intercultural competence.

The questionnaire is structured on two dimensions, namely: Perceptions regarding the role and importance of intercultural competence and The need to develop a training/development program for intercultural competence.

Each of the closed items of the questionnaire is evaluated according to the 5-step Likert scale (1-not at all, 2-a little, 3-rather, 4-much, 5-very strong). The questionnaire was administered through Google Forms, and accessed through a link, data collection being carried out between January and February 2019.

For the Dimension of Perceptions regarding the role and importance of the intercultural competence of the Questionnaire, an internal consistency index of 0.81 was obtained, and for the Dimension The necessity of elaborating a training/ development program of the intercultural competence, an internal consistency index of 0.89 was obtained, which means that the items strongly correlate with the scale for the sample of this research. The global index of internal consistency alpha Cronbach was equal to 0.90 . 


\section{Results}

The importance given by the military students to the intercultural competence in adapting to a new culture, which will leave in the international mobility stage, was evaluated by the first 4 items of the first dimension of the Questionnaire (O1).

Thus, all 45 students said that intercultural competence is important in the context of today's society. $42.2 \%$ (19 students) of them consider that they have a great deal of this kind of competence, and $6.7 \%$ (3 students) much.

In addition, the reasons why students consider intercultural competence to be important are highlighted in the figure below.

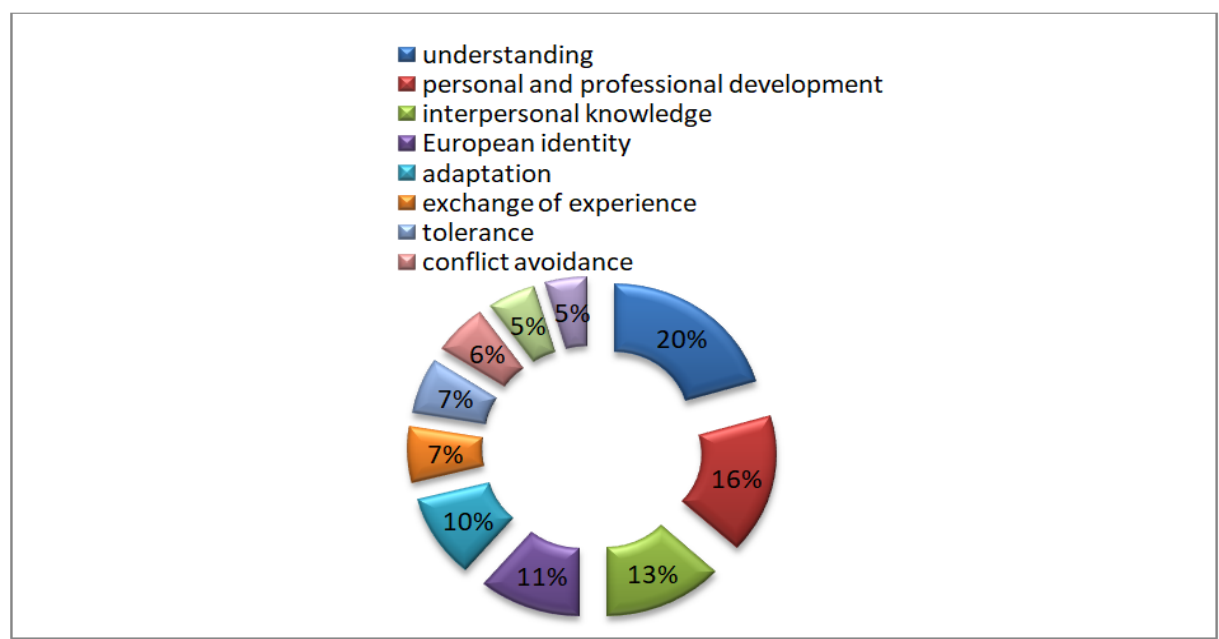

Figure no.1: Graphical representation of the students' answers to item 2.2

On the other hand, a student with a high level of intercultural competence has knowledge about: openness to other cultures; empathy; good relations with members of the different groups; tolerance for diversity; cultural shock management; methods of group integration; conflict mediation; the socio-cultural environment of the host country; managing stress and conflict situations; the language of the host country;

The distribution of student responses can be seen in the figure below. Thus, students are of the opinion that the first place is the openness to other cultures, and the last one in order of importance given is the knowledge of the language of the host country.

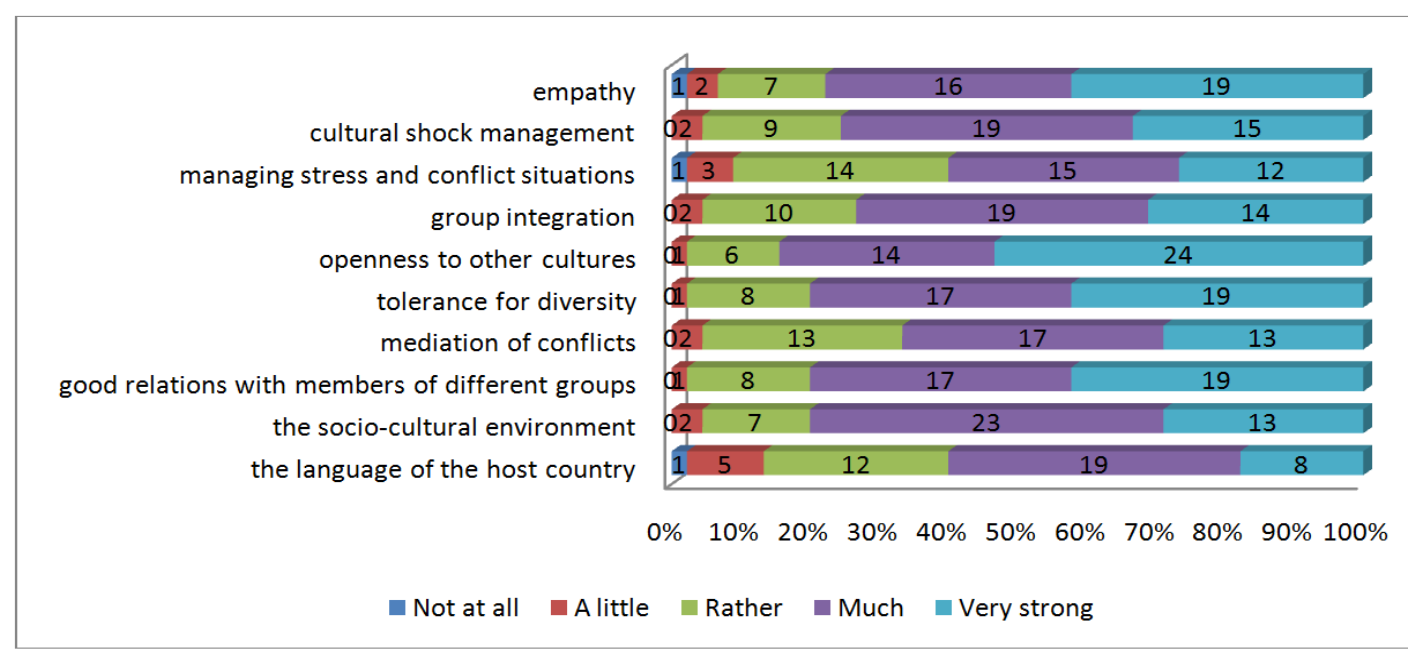

Figure no. 2: Graphical representation of the students' answers to item 3 
At the same time, another component of the intercultural competence is the effective communication, of which the elements have been classified by the students thus (Figure no. 3.): to have the ability to understand the messages of the interlocutor is the first, and to know the language of the interlocutor occupies on the last place.

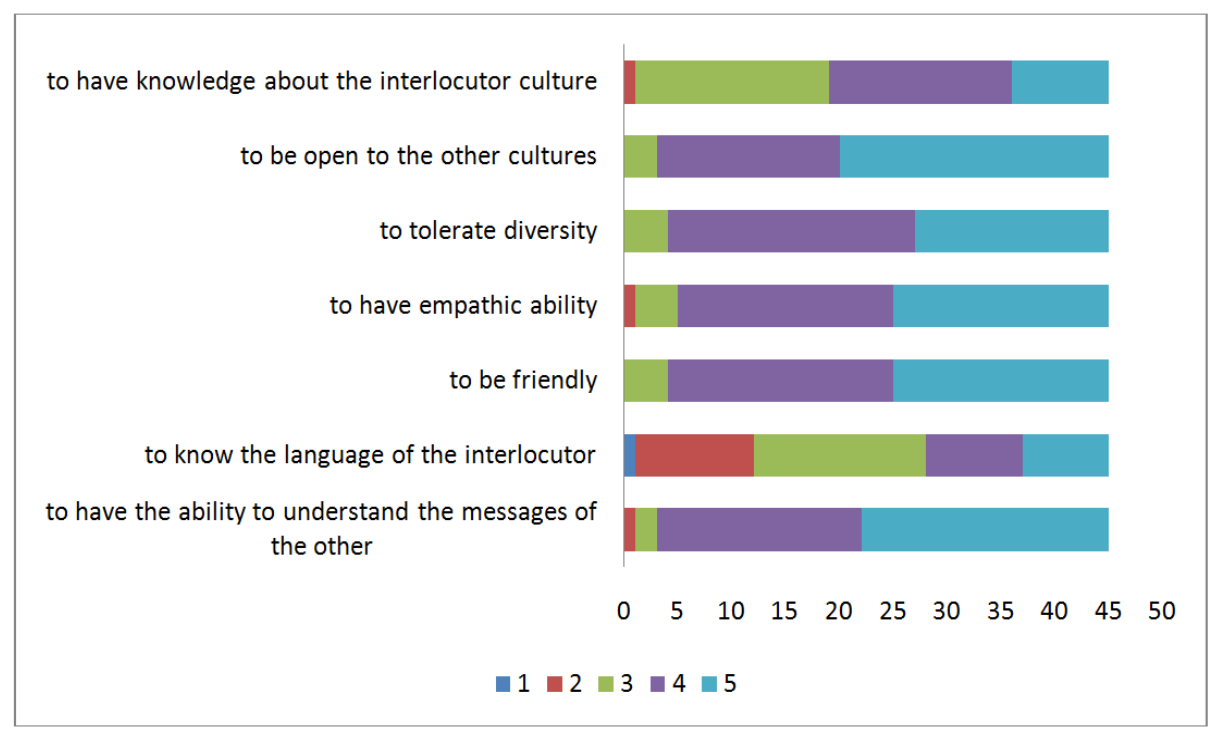

Figure no. 3: The elements of efficient communication

In order to achieve the $\mathrm{O} 3$ objective, according to which this study aims to identify the possible difficulties and obstacles of cultural adaptation that will be encountered by the Romanian students during the international mobility stage, the answers to item 5 were first analyzed To what extent do you consider that the following obstacles have a negative effect on the adaptation to a new culture?

Thus, according to the answers given by the students, not knowing a foreign language is the most important obstacle, followed by prejudices and stereotypes, and in the last place is the ignorance of the language of the host country (Figure no.4).

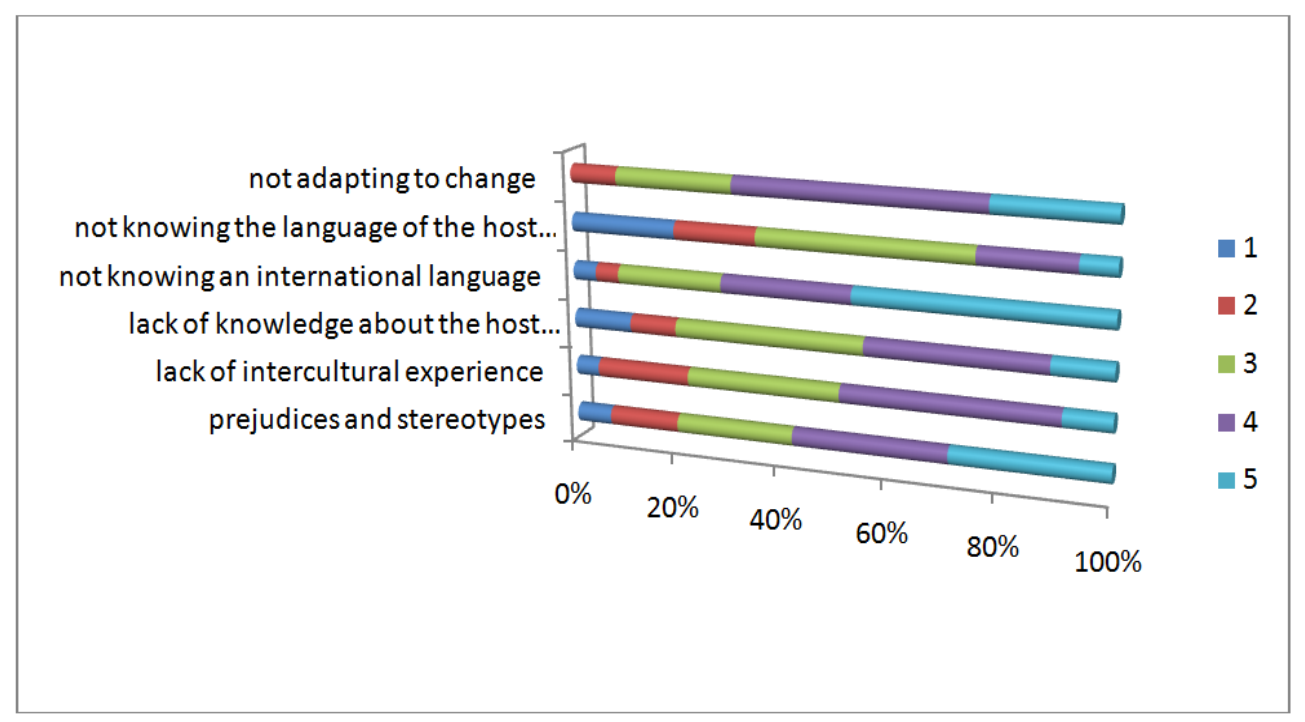

Figure no. 4: Difficulties and obstacles in cultural adaptation 
On the other hand, to give us an overview of the problems that might arise in the international mobility stage, we will continue to present the difficulties that Romanian students might encounter in another cultural context.

In Figure no. 5 it can be observed that the first difficulty is represented by the occurrence of the cultural shock upon contact with the new culture, the second place is occupied by the difficulties of adaptation and the last place is occupied by the difficulties of communication in a foreign language.

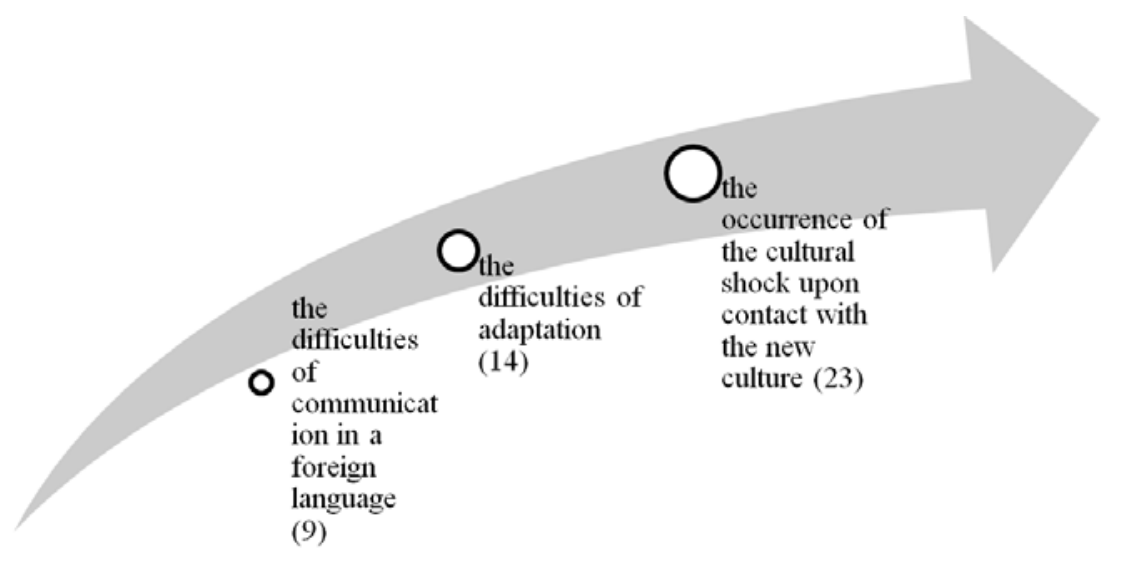

Figure no. 5: Anticipated difficulties during the stage period

In this article we also sought to reach the fourth objective according to which we analyze the students' opinions regarding the legitimacy of a program of training the intercultural competence and its desirable characteristics.

Thus, in the questions that measured the necessity of a program of training of intercultural competence and the interest of students for such courses, 39 of the participants argue that a program of training of intercultural competence is necessary. At the same time, 15 of the students would participate in such a program to much, and 13 of them would participate to very strong.

Students from the military field, at the same time, argue that a training program should discuss: The concept of intercultural competence. Theories and models, Intercultural communication, Intercultural sensitivity, Intercultural adaptation, Cultural shock management, Stereotypes and prejudices, Intercultural conflicts: management and solutions, Profile of the competent intercultural student and Cultural elements (Figure no.6).

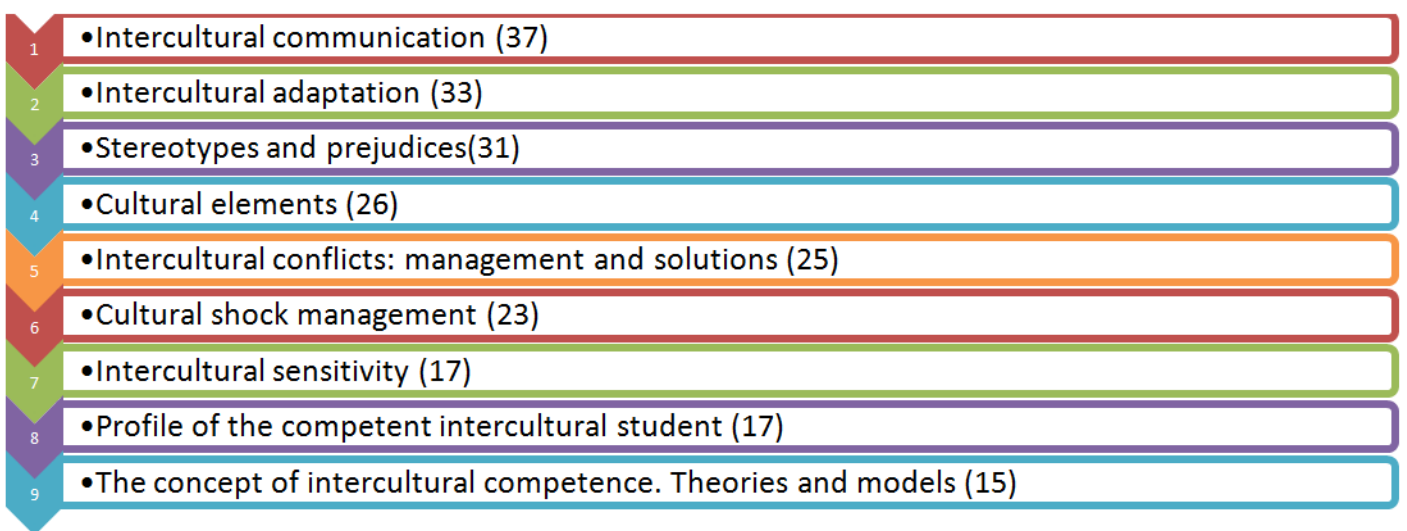

Figure no. 6: The contents of a program for training the intercultural competence 
Last but not least, according to the opinions of students in the military domain, a program for training intercultural competence contributes to the following: cooperation and good practices, acceptance of diversity and equity (Figure no. 7).

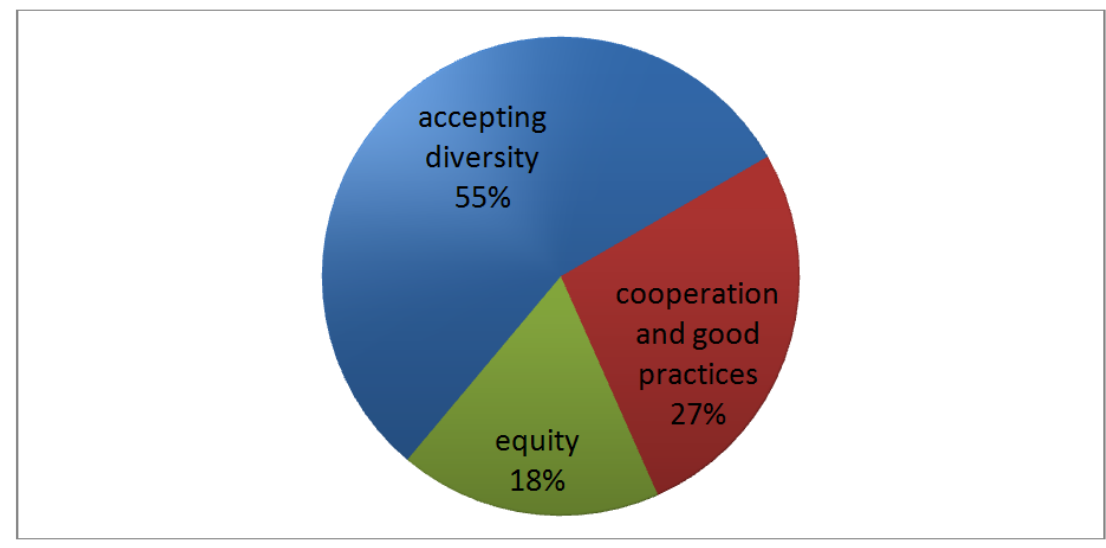

Figure no. 7: The benefits of the training program achieved.

In conclusion, all the objectives were

\section{Conclusions and Discussions}

In this study, we aimed to analyze the opinion of the military students on the importance of training and developing intercultural competence in the context of today's society. Thus, we learned that this competence helps the personal and professional development of the one who has it, but also that a training program of this kind of competence is necessary for a better relationship with the members of different cultures and for an adaptation to a different environment.

Although the conclusions cannot be extrapolated, they draw the attention of teachers to the importance of intercultural competence in students' lives, as they can interact in the university environment with members of different cultures.

\section{REFERENCES}

Hiller, G. G., \& Wozniok, M. (2009). Developing an intercultural competence program at an intercultural cross-border university. Intercultural Education, Vol. 20, 113-124, available at: https://www.tandfonline.com/doi/abs/10.1080/14675980903371019, accessed on 03 October 2019.

Hiller, G. G. (2010). Innovative methods for promoting and assessing intercultural competence in higher education. Proceedings of Intercultural Competence Conference, Vol. 1, 144-168, available at: https://cercll.arizona.edu/wp-content/uploads/sites/5/ 2017/07/hiller.pdf, accessed on 03 October 2019.

Zumbehl, H. (2010). Designing an intercultural program to prepare students to study abroad. Proceedings of Intercultural Competence Conference, Vol. 1, 424-439, available at: https://cercll.arizona.edu/wp-content/uploads/sites/5/2017/07/zumbihl.pdf, accessed on 03 October 2019. 